\title{
Contesting sustainability in urban transport - perspectives from a Swedish town
}

\author{
Paul David Fenton and Sara Gustafsson
}

\section{Linköping University Post Print}

\section{Tweet}

N.B.: When citing this work, cite the original article.

Original Publication:

Paul David Fenton and Sara Gustafsson, Contesting sustainability in urban transport perspectives from a Swedish town, 2015, Natural resources forum (Print), (39), 1, 15-26. http://dx.doi.org/10.1111/1477-8947.12061

Copyright: Wiley: 24 months

http://eu.wiley.com/WileyCDA/

Postprint available at: Linköping University Electronic Press

http://urn.kb.se/resolve?urn=urn:nbn:se:liu:diva-114291 


\title{
Contesting sustainability in urban transport - perspectives from a Swedish town
}

\begin{abstract}
This paper presents findings from a document study, survey and workshops held in a Swedish municipality. The empirical focus of the study is on the role of transport in municipal planning and transport's potential contribution to urban sustainability in the municipality. The case study highlights a problem familiar to many municipalities - a transport sector largely dependent on fossilfuelled private vehicles generates significant impacts on the climate and environment, along with other economic and social costs. However, despite awareness of these negative impacts, it is difficult to implement measures to reduce use of private vehicles and enable transition towards a sustainable transport sector.

In Sweden, municipalities have exclusive planning monopolies and an extensive range of other powers. Despite this, many municipalities are struggling to reduce car dependency and enable sustainable mobility. This paper questions the extent to which the municipality and its governance processes are capable of contributing toward sustainable development, both locally and globally, in the absence of radical measures. In particular, the paper considers why, despite having adopted objectives to promote sustainable mobility, does the municipality struggle with implementation of measures to enable sustainable mobility? Why is there a difference between words and actions?
\end{abstract}

\section{Keywords}

Municipalities; sustainable development; transport; mobility; decision-making; governance

Sara Gustafsson is an Assistant Professor and Paul Fenton is a Ph.D. Candidate at the

Division of Environmental Technology \& Management, Linköping University, Sweden,

Emails: sara.gustafsson@liu.se, paul.fenton@liu.se 


\section{Introduction}

Industrialisation, urbanisation and demographic changes have, in recent decades, led to concerns about anthropogenic impacts on the environment. Such developments informed the conceptualisation of "sustainable development" as a loosely-defined framework for addressing environmental, economic and social concerns in a harmonious way (Brundtland, 1987; United Nations Conference on Environment and Development, 1992).

Attempts to operationalise "sustainable development" have often been focused on locallevel activities, initially through the platform of Local Agenda 21 (United Nations Conference on Environment and Development, 1992). Such efforts have emphasised the central role of municipalities in addressing environmental, economic and social concerns. Sustainable urban development is thus considered an important objective for many communities around the world. By 2020, approximately half of the world urban population will live in communities with populations of less than 500,000; and in Europe, between $60-72 \%$ of citizens will live in communities of this size (around 370 million in the European Union) (UN-HABITAT, 2012).

Small-medium sized municipalities play multiple roles in the process of urbanisation (Baycan and Nijkamp, 2012; Cook and Swyngedouw, 2012; McManus, 2012; Turcu, 2012). As such, it is important to understand the formal mechanisms used by municipalities to address sustainability concerns in urban planning (Rydin, 2010). Moreover, it is important to consider the role of informal mechanisms in such processes, e.g. the individual assumptions, preferences or heuristics informing political choices, decision-making, and even the basic conceptualisation of sustainable urban development at the local level and its relationship with global concerns.

Many observers have noted a dissonance or incongruence between the stated objectives and preferences of individuals and their actual behaviour concerning sustainability issues. Such incongruence has conventionally been considered an individual phenomenon. However, incongruence may also occur when groups of individuals in the same organisational setting share similar positions and thereby replicate individual incongruence across the organisation. In other words, individuals may systematically act against their stated interest in an organisational setting. Incongruence between words and actions concerning sustainability has been observed in many studies on sustainable urban development (see for example, Bahia Schlee et al, 2012; Ceron Castano and Wadley, 2012; Ellis, 2012; Finn and McCormick, 2011; Vallance et al, 2011).

This is critical, because, as Mori and Christodoulou (2012) argue, "sustainability is not a relativistic concept, since the biophysical limits to sustaining life on Earth are absolute... sustainability should be judged by certain standards like biophysical or ecological thresholds". This point is echoed by others, such as Ceron Castano and Wadley (2012), who state that "benchmarks used to measure the sustainability of urban systems rarely comply with these 'strong' ecological requirements". 
Thus, although a city or country may be "considered sustainable in a relative evaluation, it may be non-sustainable in absolute terms. Measuring relative performance is meaningless if all countries are on unsustainable trajectories." (Mori and Christodoulou, 2012) In other words, sustainable development is often incorporated into strategies or policies, and individuals often express support for sustainable development in principle; however, implementation leaves much to be desired, and even where implementation of policies are successful, the results may not contribute to an absolute increase in sustainability.

In this context, municipalities may be expected to respond in different ways. For example, municipalities keen to achieve sustainable development may be expected to formulate more aggressive policies, and push for "no lose" options (i.e. policies that may be implemented with relative certainty and significant results). In contrast, other municipalities may be reluctant to be "first movers", perhaps because they consider a need for others to take greater responsibilities, or they perceive negative political consequences to a bolder approach. Smith and Wiek (2012) cite "departmentalism, incrementalism, and self-reliance" as three factors influencing the extent of municipal inaction (Smith and Wiek, 2012).

Institutional factors may well play a role in the development and implementation of municipal strategy and policy (McGuire, 1993). Nonetheless, it is unclear to what extent individual and group psychology influences processes to develop such strategies and policies, and shape the form and composition of institutional mechanisms established or used during implementation. For example, if stakeholders accept sustainable development to be an important concept and commit to achieving sustainability in their municipality or contributing towards improved global conditions, why then would they pursue paths of implementation that counteract their stated intention? Institutional or political factors may influence their choices, but so too may personal assumptions, preferences and heuristics.

As this issue has not been studied extensively, this paper attempts to explore and illustrate ways in which theoretical perspectives from political psychology may be used and potentially contribute to research on urban sustainability. Political psychology is interdisciplinary in character and encompasses a diverse range of methodological approaches and topics, addressing e.g. personality traits (see e.g. Altemeyer 1996), political behaviour and opinions (see e.g. Althaus, 1998; Zaller and Feldman, 1992), leadership (see e.g. House and Howell, 1992), or individual and group dynamics (e.g. Milgram, 1974).

The study of political psychology provides insights into, amongst other things, the heuristics, values and emotions shaping and informing decision-making in political situations (Hermann, 1986). As such, use of theoretical perspectives from political psychology may contribute to improved understanding of underlying assumptions or agendas influencing the operationalisation of sustainable development in urban contexts. In this paper, findings from an exploratory study of a Swedish municipality provide the empirical basis for this discussion, which focuses on apparent incongruence between opinions and actions. 


\section{The curious case of Norrköping}

The case of Norrköping helps to illustrate the relevance of some of the theoretical discussions concerning urban sustainability. Below, the national context informing the case of Norrköping is described, along with a description of Norrköping and its transport policies.

\subsection{Swedish municipalities struggle to reduce transport emissions}

Norrköping is located in Sweden, a country often considered advanced in debates on sustainable development and somewhat unique with regard to municipal government. Wollmann (2008) notes that Sweden has a longer history of municipal self-government than most European countries and that Swedish municipalities have a constitutional mandate with significant powers, including taxation. However, municipal portfolios and responsibilities are diverse and vary considerably within the country (Fredriksson, 2011).

Swedish municipalities have played an instrumental role in advancing many aspects of sustainable development through Local Agenda 21 and other mechanisms. In some sectors, particularly district heating, this has resulted in substantial reductions of greenhouse gas emissions (IEA, 2013). However, the picture is mixed in the transport sector. Roles and responsibilities vary between the national (e.g. major road and rail infrastructure, airports, ports), regional (e.g. public transport), and local levels (e.g. urban planning, in some cases owner of airports and ports). Over the past two decades, a diverse cocktail of pilot projects have encouraged innovation through measures such as introduction new vehicle or fuel types, congestion charging, extension of cycling infrastructure, etc. Experimentation has in some cases led to widespread adoption and policy changes (see e.g. Johnson and Silveira, 2014).

Nonetheless, domestic transport accounts for 33\% of national greenhouse gas emissions, of which $95 \%$ are caused by road transport. The national total rises to $47 \%$ of greenhouse gas emissions when including maritime and aviation emissions (Trafikverket, 2014). On the roads, benefits from incremental improvements in vehicle and fuel technology have been consistently offset by increases in the total distance travelled by road users. Like many other countries, Sweden remains highly dependent on use of private cars. However, whilst longdistance transportation may be difficult to reduce in a large, predominantly rural country like Sweden, it is possible to envisage reductions in road transport in urban areas.

Reductions in the volume of urban road transport would not only offer potential to reduce greenhouse gas emissions, but could also provide co-benefits in terms of local air quality, traffic safety, or urban environment (depending, of course, on the form and content of any such changes). However, if such reductions are to be achieved, alternative provision of transport is necessary to enable replacement through modal shift, or alternative visions of urban space must be conceptualised and realised to enable a redefinition of urban mobility. These are important challenges for municipalities in Sweden and local governments around the world. 


\subsection{Transport as a municipal challenge}

Norrköping has a population of around 130,000 residents and is a regional centre, with a large port and logistics hub, close proximity to major road and rail links, and a mixed economy. Norrköping has worked with sustainability issues for several decades, for example through its Local Agenda 21 program. However, in common with many other municipalities, Norrköping still faces a number of sustainability challenges, including e.g. local air pollution, energy demand, urban sprawl and socio-economic problems.

Transport is a challenge that arises from, is interrelated with and contributes to some of these other challenges. As in most countries, the transport sector - and especially road transport - is largely dependent on fossil fuels and as such, is a significant source of global greenhouse gas emissions. Norrköping faces a number of complex challenges concerning transport and mobility, particularly in relation to its other work for sustainable development.

For example, the municipality's size, topography and the location of existing transport infrastructure imposes certain directional flows on north-south and east-west axes. The town centre has a historic grid street plan, whereas outlying districts are more characterised as urban sprawl; reflecting this trend, significant retail centres have developed outside of the town centre. The proximity of these centres to national highways reinforces the municipality's status as a regional hub, yet also increases the likelihood of further sprawl outwards. This in turn influences transport patterns within the urban area, as businesses move out and distances between residences, workplaces and services increase.

As stated above, the municipality's economy is partly dependent on its good infrastructure and location, meaning transportation is considered a necessary condition for sustainable development of the municipality's economy and society. Nevertheless, sustainable development also concerns environmental issues, ranging from e.g. local air pollution or land use change, to greenhouse gas emissions and unseen, up- or downstream impacts of resource consumption. Thus, municipal efforts to increase sustainable development necessarily involve reasoning around the relationship between economic, social and environmental dimensions and, to some extent, identification of appropriate trade-offs or realisable policy objectives.

\subsection{Transport policy in Norrköping}

A document study was conducted to assess the recent history of transport policy in the municipality and determine relative levels of transport demand. The researchers gathered publicly-available documents published by the municipality to compile lists of previous and current targets, policies and measures. The document study showed that, during the past 15 years, Norrköping had repeatedly formulated clear statements expressing its intention to increase the sustainability of its transport system, reduce use of cars and prioritise other modes of transport. For example, there was political consensus on the importance of addressing negative impacts arising from transport, and on the strategic objective that "the 
need for transportation within the municipality should reduce and transportation that occurs should be as sustainable as possible"(Norrköpings kommun, Municipal Target 15, 2011).

Stated objectives included the reduction of air pollution, greenhouse gas emissions, road accidents, and improvements to public transport, increased accessibility, etc. A mix of physical and non-physical measures had been adopted to achieve fulfilment of these objectives, including changes to road layouts to encourage pedestrians or cyclists, introduction of speed bumps, lowering of speed limits, etc. Three key instruments of municipal planning are clearly described in the municipality's Guidelines for Transport from 2011:

- "Planning tool 1" is the "four-step principle", an approach commonly referred to and used in Swedish transport infrastructure planning. The four-step principle involves prioritising (1) measures to reduce or change the need for transportation; (2) measures to improve efficient use of transportation; (3) limited physical measures; and (4) large-scale investments in physical infrastructure. In other words, the principle should be implemented in all physical planning to minimise the need for transport, make necessary transportation more efficient, and limit the scale of interventions in the physical environment and infrastructure investments.

- "Planning tool 2" is the "Order of Priorities" for transportation in the urban area, by which the municipality should - in all planning - aim to prioritise (1) walking and cycling, (2) public transport, and last, (3) cars for passenger journeys. In other words, cars should be considered only after other modes of transport and only (in line with the four-step principle) if the journeys required are absolutely necessary.

- "Planning tool 3" is "Sustainable mobility", an approach aiming to increase use of sustainable forms of transport. Norrköping identifies several types of measure that should be used to achieve sustainable mobility, namely - influencing passenger knowledge, attitudes and behaviour; influencing decision-makers knowledge, attitudes and behaviour; using economic incentives and regulations to influence choice of transport; and use of new techniques. Additionally, physical planning and physical measures may be used. (Norrköpings kommun, Guidelines for Transport, 2011)

In other words, the municipality's political and institutional frameworks have been conscious of the need to address sustainable development and particularly transport, and committed themselves to specific measures using the aforementioned planning tools. Nevertheless, the document study revealed a number of recurrent problems and evidence of inconsistent, incomplete or partial implementation of some policies or measures (e.g. recurring problems with air pollution or accidents at the same locations). However, the failure to achieve stated 
objectives did not result in adoption of substantially new approaches, but rather a reiteration of past objectives and measures.

Indeed, in more recent policy documents, this has been done in a less specific way than earlier documents, with targets referred to in general, rather than quantifiable, terms. The municipality justifies its non-specificity by referring to changes in institutional routines which have seen targets removed from long-term strategies and placed within annual work plans. One practical consequence is to make municipal objectives more unclear and incremental. Moreover, this practice departmentalises multidimensional, interdisciplinary, or crosssectoral issues, in a way that risks obstructing achievement of long-term strategic objectives. As a consequence, the municipality's recent strategic documents may be interpreted as offering general indications of what the municipality considers desirable, yet little indication of how, when or with which means these will be achieved. This, in the context of sustainable development, is most problematic.

\section{Survey}

The document study highlighted dissonance between long-standing objectives and performance. To investigate why this dissonance occurs, the researchers decided to conduct a short survey, to explore how a select group of stakeholders reason around the role of transport in urban planning. The survey was created using the SurveyMonkey online tool and distributed to recipients on 3 May 2012, with responses required by 22 May 2012.

\subsection{Recipients}

The survey was distributed to a select group of individuals, who had previously been invited to a workshop on transport planning in Norrköping. This workshop was held on 25 May 2012. The composition of this group was determined by the researchers, following discussions with a municipal contact person and with reference to the document study. Invitees were selected on the basis of their role, knowledge or history of engagement in the municipal planning and the transport sector. Those invited included municipal civil servants and politicians responsible for sustainable mobility, traffic planning, urban planning, business development, and air quality. A range of other stakeholders were invited, including representatives for property owners and retailers, public transport, construction companies, logistic companies, environmental non-governmental organisations, and student groups. In total, 24 individuals received the survey directly to their personal email accounts. Of these, 12 individuals answered some of the questions in the survey, with 7 individuals completing all questions in full.

The recipients were thus considered "key informants" by the researchers, as opposed to a group representative of the wider population or particular constituency group. This was important for the purposes of the workshop, which aimed to discuss the stakeholders' 
perspectives and experiences of transport planning in the municipality, in order to identify challenges and opportunities for sustainable urban development. However, the focus on "key informants" was also important for the survey, which aimed to assess the extent to which the behaviour and opinions of recipients was consistent with the ways they perceived policy implementation for sustainable transport to actually take place. In other words, did these "key informants" practice what they preached, and did their expectations of policy match with their experience of policy implementation?

\subsection{Survey design}

The survey comprised 13 questions, the last of which concerned future contact with the researchers and is not relevant to this study. The main part of the survey concerned the recipients' role and self-perception (Q1; Q10), personal preferences and behaviour (Q2-3), and opinions (Q4-9; Q11-12). The questions concerning opinions operated as pairs, with the first question in each pair asking for an opinion of what should occur and the second asking how the recipient perceived actual implementation to occur (see example below).

For each question, a number of alternative answers were given. In some cases, recipients were asked to select single options, whereas for others they were asked to rank multiple options according to preference. For example, in Q4, recipients were asked to rank ten alternative modes of transport in response to the question "Which transport modes do you think should be prioritised in municipal planning processes?". Answers to Q4 were then compared with answers to Q5, in which a similar question "Which transport modes do you think actually are prioritised in municipal planning processes?" was asked.

The transport modes presented as alternative answers corresponded to those currently available in Norrköping (and therefore excluded modes that may be viable in other contexts). For each question, the range of answers should be considered non-exhaustive. This reflects the fact that the survey was not designed to provide a full and comprehensive picture set of answers regarding the many influences on urban transport planning, but rather to illustrate incongruencies and inconsistencies between perceptions of ideal or necessary transport and the actual planning and behavioural practices observed or undertaken by recipients. The results presented in this study are thus indicative, both of the limitations of the survey and its non-comprehensive character, yet also of the opinions of the respondents in relation to the possible alternative answers.

\subsection{Limitations}

The results of the survey are presented here and used as a framework for the subsequent discussion of the value and utility of approaches from political psychology in decision-making for sustainable urban development. The survey was limited in scope and only distributed to a small number of recipients. Moreover, respondents were asked to select alternatives from lists of options that reflected the local context and were not universally comprehensive or all-encompassing in character. As a result, the survey findings offer no more than an insight 
into how such stakeholders view the issues at stake; the results should be understood to be indicative and illustrative in nature, and the subsequent discussion should be considered in that context.

\subsection{Follow-up of the survey: workshops}

Preliminary results of the survey were presented to participants at the workshop on 25 May 2012, following a visioning exercise on urban planning and prior to a reflective discussion on sustainable urban development. The exercise and discussion confirmed the general validity and relevance of the survey findings, and subsequently provided input for the development of forecasts and scenarios for transport planning in the municipality. These were discussed at a second workshop on 18 April 2013. The volume of road transport in Norrköping was contrasted to other European examples and participants were encouraged to reflect on their roles and identify opportunities and barriers to reducing use of cars and increasing use of other modes of transport. These discussions resulted in interesting proposals, yet limited reflection as to why Norrköping had previously failed to achieve such changes, given its longstanding policy commitment towards doing so. This paper attempts to provide insight into this issue.

\section{Survey results}

\subsection{Roles and behaviour}

Questions 1-3 and 10 concerned the respondents' role and behaviour. Each question was answered by 12 respondents. Two thirds of the respondents (8) worked as civil servants, whereas 1 respondent was a politician and 3 worked in other roles (Question 1).

Subsequently, in Question 10, respondents were asked to reflect on their role in municipal planning and identify the extent of their influence. Of the 10 responses to this question, none stated they had very little influence or no influence. $20 \%$ claimed to have little influence, and $40 \%$ neither large nor little. However, 30\% said they have large influence, and 1 respondent claimed to have major influence. Thus, all of the respondents claimed to have influence, and $40 \%$ claimed significant influence.

Responding to Question 2 - When you travel more than $1 \mathrm{~km}$ within the municipal boundary, which modes of transport do you prefer to use? - half of these individuals selected cars (3) or cycles (3) as their preferred mode of transport from a list of seven alternatives. The other individuals preferred bus (2) or walking (2), tram (1) and train (1).

In Question 3 - How often do you use...? - the respondents were asked to provide one answer for each of the transport modes listed above. Answers could be selected from a list including: daily (several journeys); daily (return trip); several days a week; once a week; irregularly (at least once a month); irregularly (at least once per year); never; and don't 
know. The responses to Question 3 showed that trains and trams were used most infrequently, whereas walking was most common (80\%, 10 respondents).

Cars were the only transport mode used by all respondents to some extent, with $75 \%$ of 12 respondents replying that they used cars more than once a month. Cycles were used less frequently than walking or cars, but more frequently than buses. These answers provide a basic picture of the respondents as a mixed user group, expressing preferences for cars and cycles but often walking or using cars for their regular journeys.

\subsection{Opinions and perceptions}

In Questions 4-9, respondents were asked a series of questions concerning transportation within the municipal boundary. Answers were to be ranked according to different criteria.

In Question 4, respondents were asked "Which transport modes do you think should be prioritised in municipal planning processes? Respondents were asked to rank from 1 (highest priority) to 10 (lowest priority) the following transport modes: cars (local journeys); cars (regional/national journeys); local buses; regional/inter-city buses; cycles; walking; rail freight; road freight; trams; train; other; or don't know.

The responses to Question 4 (see Figure 1) indicated a strong preference for prioritisation of walking, cycling and trams. There was less support for prioritisation of local or regional buses, train and goods transport. The majority of respondents felt that cars should be ranked in places 8-10 for both local and regional/national journeys, meaning there was strong opposition to the prioritisation of cars.

Question 5 was similar in design and focus, but asked respondents "Which transport modes do you think are actually prioritised in municipal planning processes? Responses indicated that a majority think that the municipality actually prioritises cars making local journeys, local buses, and to a lesser extent, trams and trains. Respondents considered the municipality viewed other transport modes as lower priorities.

It is perhaps no surprise that there respondent's perceptions about what should be prioritised differ from their experiences of what is actually prioritised. These differences are illustrated in Figure 1, in which the black columns represent answers to Question 4 and the grey columns represent answers to Question 5. On the left, we can see that respondents consider that cars (both local and regional/national), freight (both road and rail), and the combined category public transport (buses and trams) should be low priorities, but experience them to be highly prioritised. The opposite is observed for cycling and walking, and the single category for trams. This results in a significant distortion in favour of cars. 


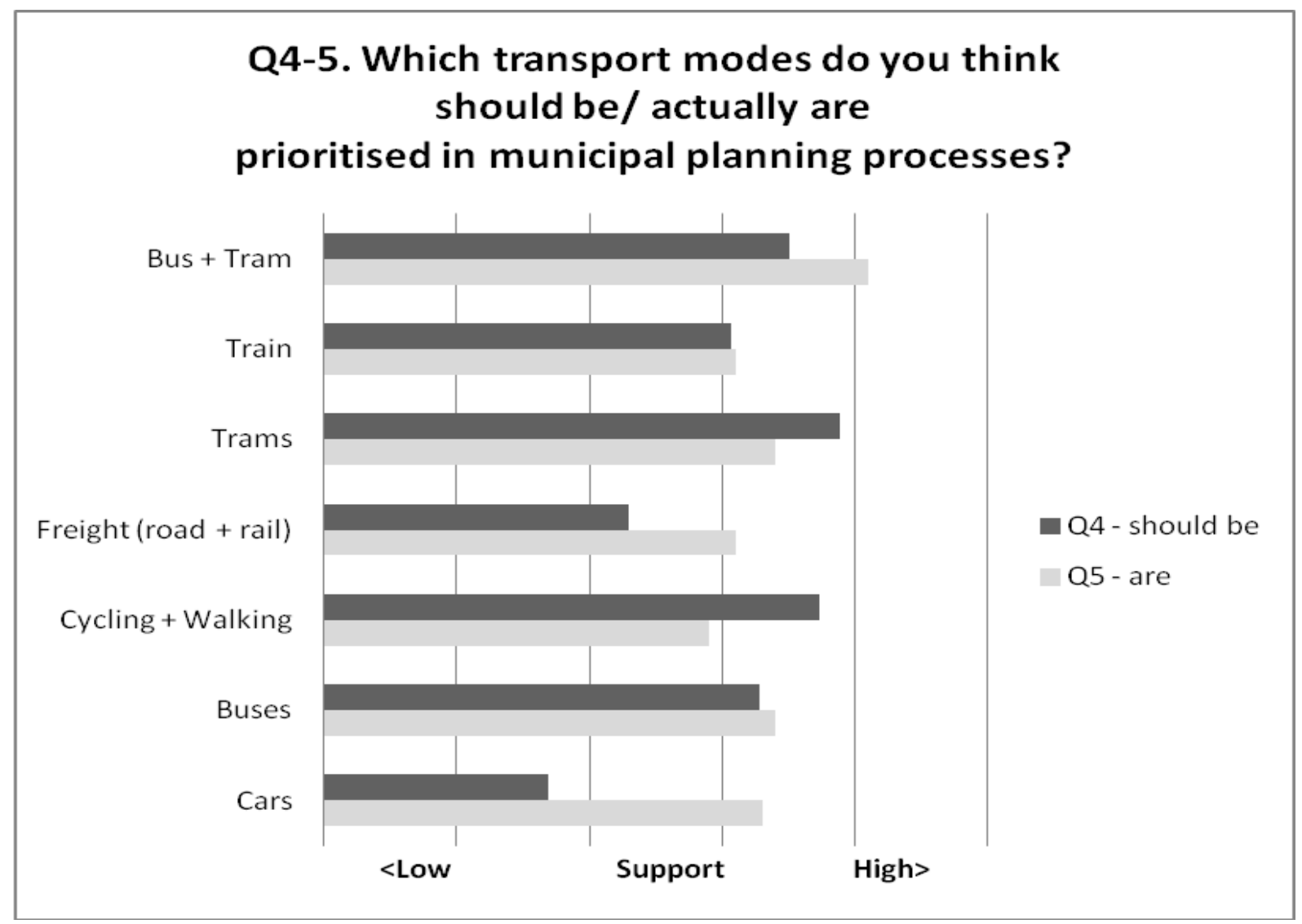

Figure 1 - differences in responses to Questions 4-5.

Question 6 - How important do you consider it is to increase use of these modes of transport in the municipality during the next decade? - involved ranking the transport modes listed in Questions 4-5 as either: essential, important, sometimes important, rarely important, unimportant, or don't know.

Responses to Question 6 included strong support for increasing use of rail ( $100 \%$ essential), followed by cycling, trams and walking (100\% important-essential), local buses, rail freight and regional buses. Road freight received mixed responses, whereas regional/national car journeys were considered generally less important, with local car journeys considered largely unimportant ( $77.8 \%$ rarely-unimportant and $0 \%$ essential).

Question 7 reverses the emphasis in Question 6, by asking - How important do you consider it is to reduce use of these modes of transport in the municipality during the next decade? Here, responses were more uniform than in Question 6. Respondents saw no strong reasons to reduce walking, cycling, or use of buses, trams or trains. That said, respondents were in favour of reductions to road freight and use of cars, in particular for local journeys.

These results are illustrated in Figure 2, with the black indicating answers to Question 6 (increase) and the grey indicating answers to Question 7 (decrease). The illustration shows clear preferences, although responses appear to have been more equivocal in the case of goods transport and for cars. Generally, the responses to Questions 6-7 underline the results 
shown in Questions 1-5, and imply a need to increase use of all forms of transport with the exception of cars, or the need to reduce only use of cars and road freight.

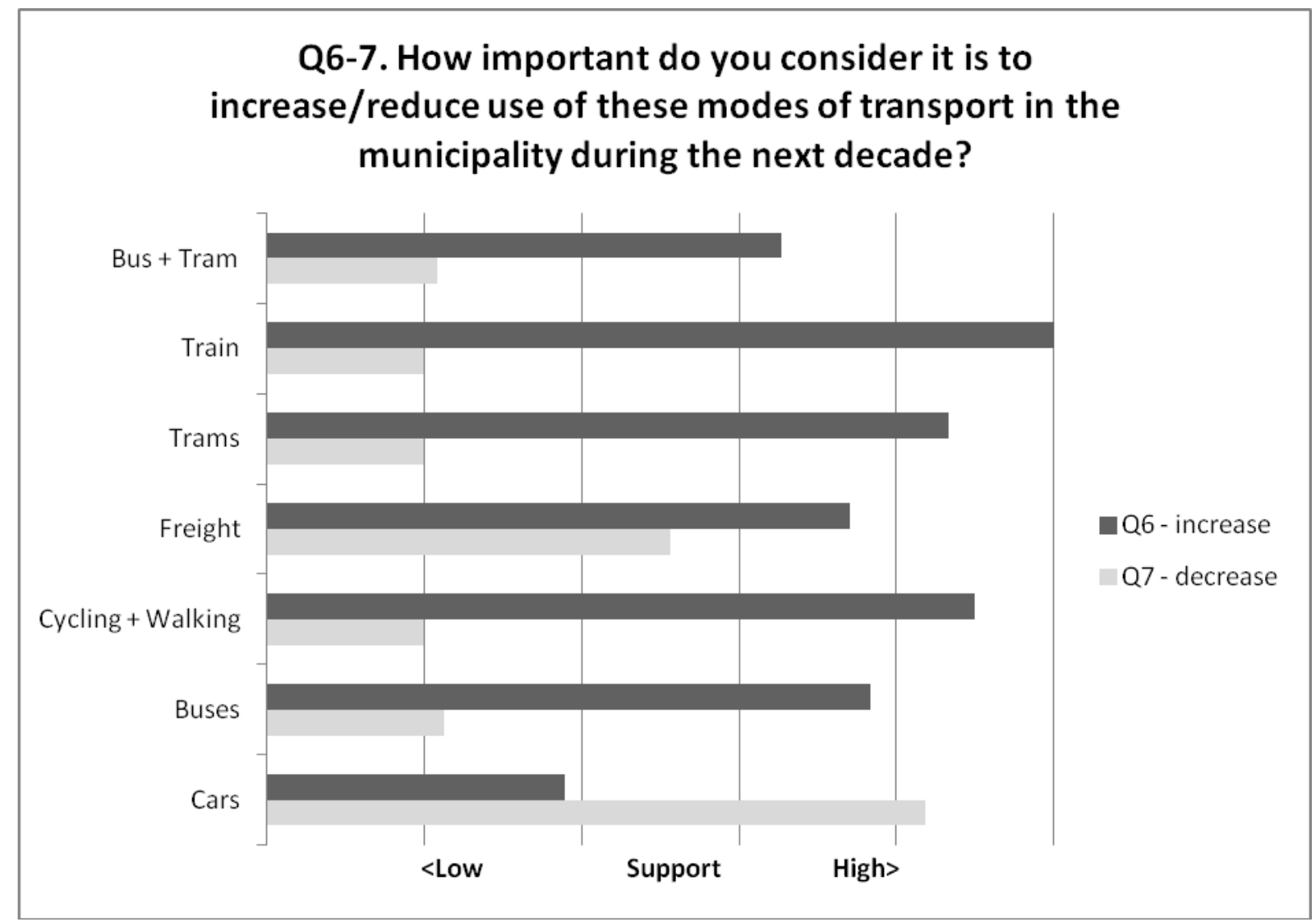

Figure 2 - differences in responses to Questions 6-7.

Questions 8-9 changed the emphasis of Questions 6-7 slightly, asking respondents "How likely do you think it is that use of the following transport modes will increase in the municipality during the next decade?" and an equivalent question for reduction. Possible answers included: highly probable, probable, not especially probable, unlikely, very unlikely, or don't know.

Responses to Question 8 (increase) showed that most respondents felt that increases would be observed for all modes of transport. Respondents considered increases for cars (local and regional) and road freight as most probable, followed by cycling, train and rail freight, and to a lesser extent, trams. However, responses to Question $\mathbf{9}$ (decrease) indicate uncertainty about the degree to which reductions in local car traffic are probable, plus some degree of pessimism about buses. Respondents considered it highly improbable that reductions would occur to road freight and to lesser extents, walking, cycling and journeys by train. The differences are illustrated in Figure 3, with the black indicating answers to Question 8 (increase) and the grey indicating answers to Question 9 (decrease).

Again, comparison indicates clear preferences and a reasonable degree of certainty, with cars considered the most likely to increase. However, buses provide an exception. Some 
respondents use buses (Questions 2-3) and generally, respondents consider buses should be and are being prioritised at an appropriate level (Questions 4-5). Moreover, respondents consider it to be important that the use of buses increases rather than decrease in the coming decade (Questions 6-7). Despite this, respondents appear uncertain as to whether use of buses will increase or decrease (Questions 8-9), implying that a range of external factors may be generating uncertainty about the role and appropriateness of buses in the transport system.

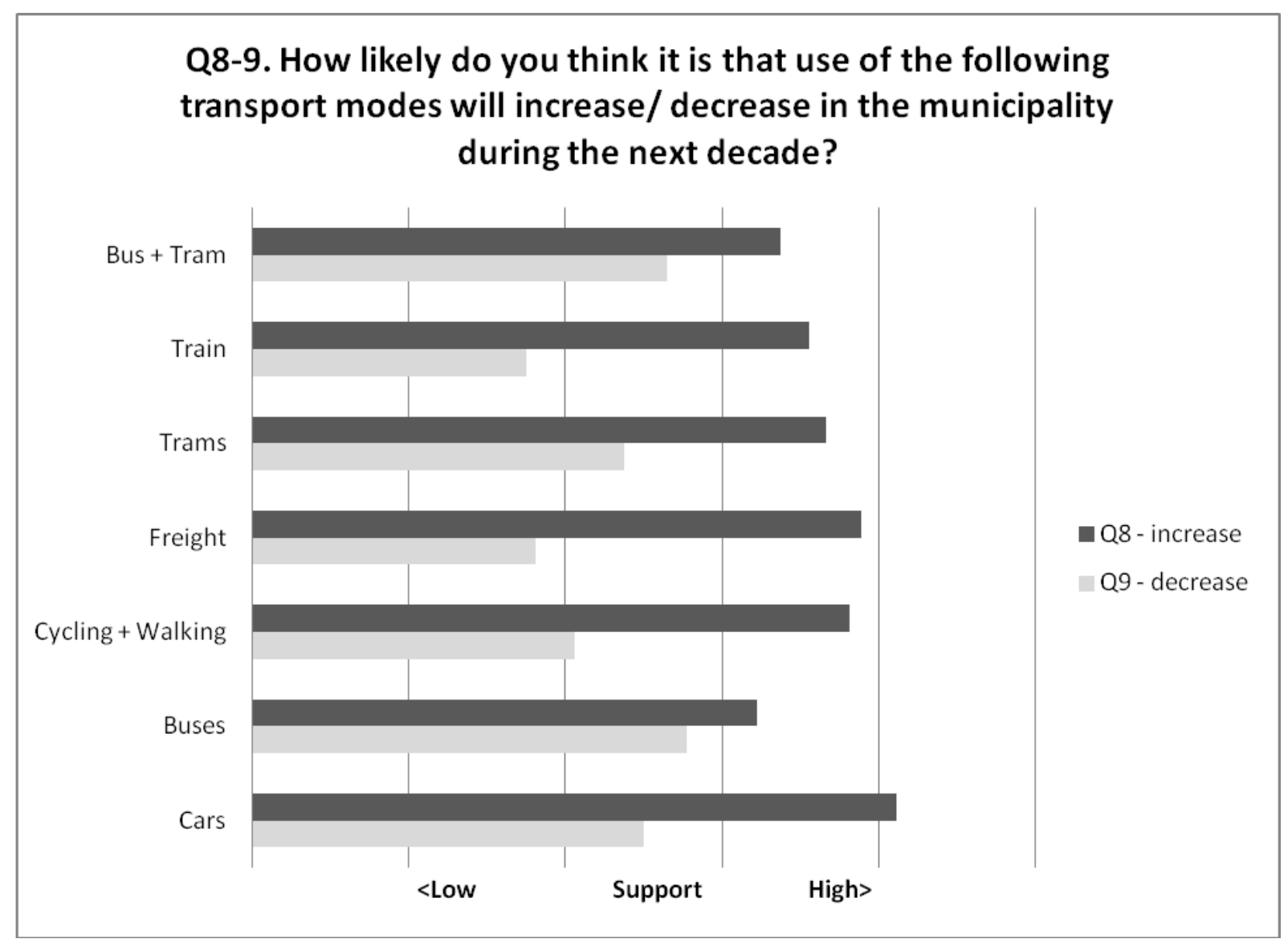

Figure 3 - differences in responses to Questions 8-9.

Question 11 presented a different theme to the respondents, asking "In an attractive town, what should the space between buildings be used for?" Respondents were able to choose from a list of categories and state a preference for prioritisation from the following options: (should) always (be prioritised); almost always; sometimes; almost never; never; or don't know.

The categories available for selection were - children/playgrounds; cars; cycling; walking; green space (parks/trees); meeting places; new construction (residences); new construction (retail/markets); new construction (offices); parking; other. A number of other categories were considered for inclusion, but left out of the survey to avoid making it too complex for respondents. 
Results suggested a strong preference for walking, followed by cycling, green space and to a lesser extent, new residences, children/playgrounds, and meeting places. Many answers were fairly equivocal, although there was a negative reaction to use of space for cars and parking, and mixed responses about new construction.

Question 12 presented a variation of Question 5, asking respondents what they considered to actually be prioritised. Responses suggested the municipality strongly prioritises transport, primarily cars and parking, but also cycling and walking. New construction of residences and retail/market premises were also considered to be prioritised, whereas children/playgrounds were considered to be under-prioritised.

Figure 4 shows the results in terms of general categories - from left to right: cars and parking, cycling and walking, new construction, living (children, green space, meeting places). As with previous questions, the results suggest a tendency to over-prioritise cars (and supporting infrastructure such as parking) in implementation, something which respondents consider undesirable.

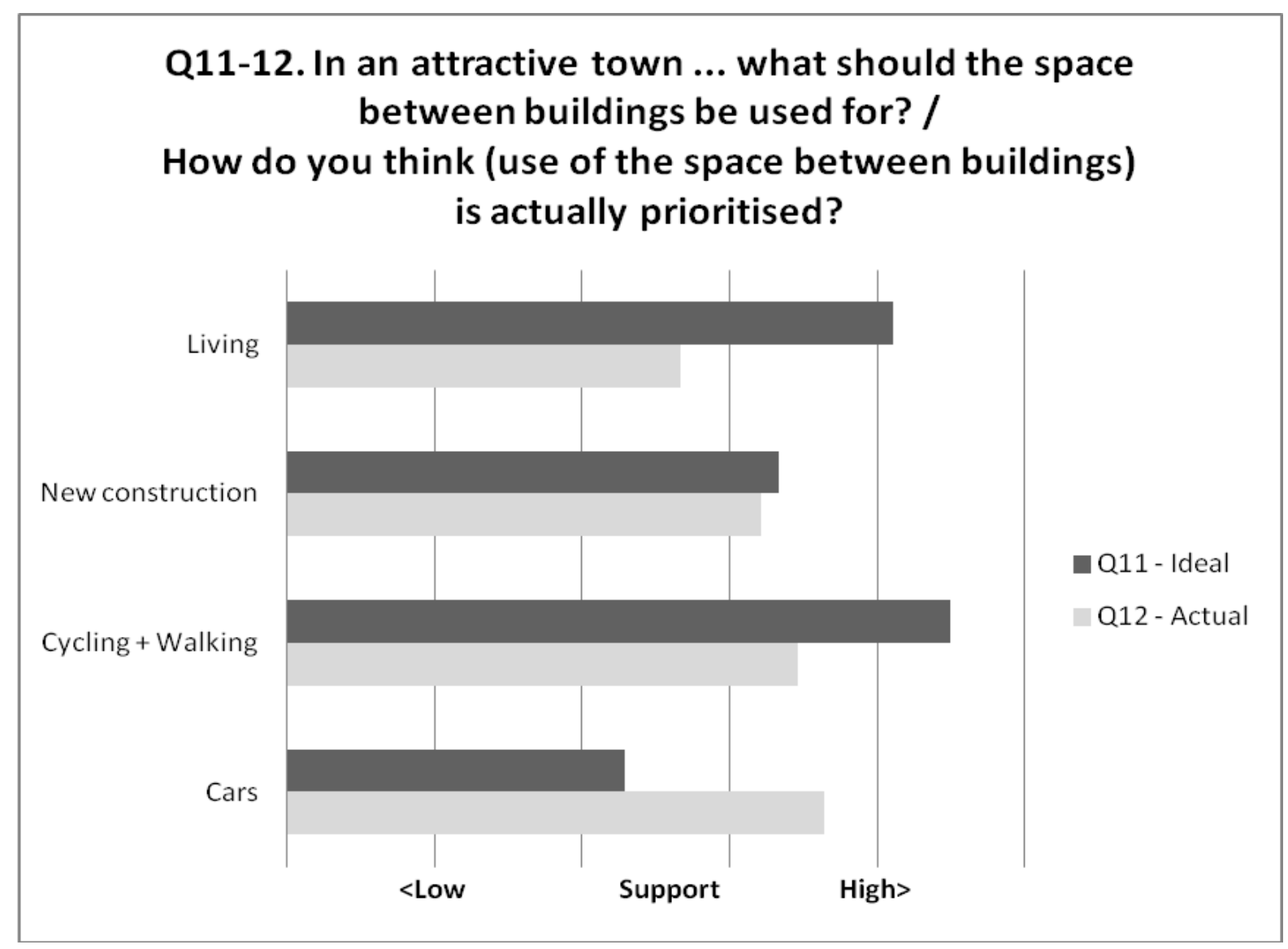

Figure 4 - differences in responses to Questions 11-12. 


\subsection{Summary of findings}

Questions 1-12 address a range of issues, including respondent's role, behaviour and selfperception of influence, as well as opinions on desired vs. perceived/experienced actual prioritisation of different transport modes in planning; perceptions about the importance of increasing/reducing use of different modes; and perceptions about the likelihood of increases/reductions occurring. In a general sense, the responses were fairly consistent in inclining towards walking, cycling and public transport as desirable objectives, whilst highlighting the de facto dominance of cars and road freight in transport.

The findings seem to not only imply that respondents experience differences between the municipality's words and actions, but also that respondents' behaviour does not reflect their statements about what is desirable for the municipality. For example, in Questions 2 and 3, respondents indicated preferences, first for using cars and walking, then cycling and buses, ahead of trams and trains; these preferences appeared to be reasonably matched by their reported behaviour. Yet, even though respondents are habitual users of cars - and prefer using this mode of transport - they think that cars are over-prioritised in municipal planning processes. This implies recognition of the need to reduce use of cars, or at least to make it harder to use cars. Similarly, despite few respondents preferring trams, or using trams, the results to Questions 4-5 show that respondents consider trams as under-prioritised in municipal planning processes. These indicative results point to an incongruence between individual preferences, behaviour, opinions and experiences, particularly with regard to cars and trams.

However, when considering the collective sum of individual incongruence, we see a pattern implying some degree of incongruence between municipal policies and implementation. As noted above, the municipality's policy objectives and planning tools - determined and approved by elected politicians - state that the municipality should reduce transport demand, change passenger behaviour, and prioritise walking, cycling and public transport at the expense of cars. These objectives are considered desirable by respondents in their answers to Question 4. However, in Question 5, the respondents imply that the municipality's stated objectives are not actually being implemented. Moreover, the respondents themselves do not behave in the way they consider ideal.

Whilst the observation of such incongruence is perhaps unsurprising, the results are intriguing when considering the background of the respondents. Given the status of the group - as "key informants" representing local politics, the municipal administration and local stakeholders - one may expect a familiarity with the formal objectives of the municipality to be evident in the results. For example, civil servants, answering in their professional capacity, may be expected to report what they are "allowed" or "expected" to say, based on policies, guidelines or norms.

Indeed, responses to Question 1 indicated that the majority of respondents worked within the municipal administration or politics. Perhaps as a result, in Question 10, responses 
suggest that respondents believe that their personal role in municipal planning processes confers upon them influence to affect the form, scope, content or outcomes of such processes. At this point, it seems obvious to wonder why there are incongruencies, given that the respondents perceive themselves as having the opportunity to influence processes and affect outcomes. We may, for example, expect to see a clearer correlation between individual behaviour and opinions - but no such correlation is evident.

A number of questions arise from this incongruence - are the respondents attempting to influence politics or political decisions in their answers? Why is there a gap between the words and practice of the municipality? Why do the opinions recorded in the survey, together with past and current policy documents, suggest that use of cars should be downprioritised and reduced, whilst behaviour and implementation points in the other direction?

The results highlight some confusion or uncertainty on the part of respondents (see Questions 8-9 concerning buses). This raises the possibility that external factors may lead to uncertainties or make it hard to interpret results. For example, although Swedish municipalities have considerable powers when compared to municipalities in other countries, they are still subject to certain constraints with regard to physical planning. Some types of major road and rail infrastructure are subject to national control, and provision of public transport is predominantly coordinated on the regional level. Thus, in certain regards, a municipality may have limited room for manoeuvre and as such, local politicians or civil servants may discount the importance of such topics as they are outside the immediate scope of their powers and activities, even if they play an influential role in defining the scope for action by imposing certain types of system changes.

In sum, the results illustrate a degree of incongruence between individual preferences, behaviour, opinions and experiences, and raise a number of questions related to the possible causes of such incongruence. It is unclear to what extent incongruence stems from external factors constraining the municipality's ability to act in accordance with the stated preferences of its stakeholders, or whether the incongruence is linked to the assumptions, behaviour, decisions and interactions of the municipality and its stakeholders. In the following section, the possibility that psychological factors may contribute towards incongruence will be explored.

\section{Analysis}

The results of the document study and survey reveal a number of curious findings. The survey respondents are a group of stakeholders that can be broadly defined as institutional insiders; they operate in a municipality which has, over a long period of time, reiterated its intention to increase sustainable development, particularly with regard to transportation. Norrköping has formally adopted measures to increase the sustainability of its transport system, and respondents clearly view a shift from use of cars to other modes of transport as 
both desirable and necessary. Nonetheless, the respondents also consider a transition away from cars as unlikely. Despite having what appears to be all the right cards (in terms of political and institutional mandate), the respondents do not trust their hand. What could the underlying reasons for this be?

Past performance may have affected the levels of trust or confidence among respondents, in the sense that non-achievement of previously stated objectives may have undermined confidence in the achievement of future objectives. If this is the case, words - even politically approved, formally adopted ones - may retain little meaning. Moreover, levels of trust or confidence may be affected by emotions or cognition (Druckman and McDermott, 2008). For example, proponents of the availability heuristic may argue that repeated exposure to failure in previous attempts to improve the sustainability of transportation may cause respondents to over-estimate the likelihood of failure in the future (Tversky and Kahneman, 1973).

In other words, pessimism is an exaggeration, an over-estimation linked to base rate fallacies, stimulated by contextual circumstances that need not necessarily be representative. Of course, in the case of transportation, there are few examples of successful attempts to dramatically reduce or limit use of cars. Pessimism may be justified, even if the few examples that do exist may point towards very clear, simple and viable ways of reducing or limiting use of cars. Thus, use of the availability heuristic or the tendency towards base rate fallacies may distort respondents' perceptions as to what is possible, leading to unconscious exclusion of possible alternatives. This may explain the lack of optimism or confidence concerning perceptions of implementation or future trends.

Affective intelligence may stimulate or interact with heuristics, generating or reinforcing such tendencies. For example, pessimism over the likelihood of achieving change using existing strategies or policies may lead to affective forecasting, in which respondents selectively imagine hypothetical solutions to the problems (e.g. new technologies, fuel types, etc), rather than actively seeking to shape the future (Wilson and Gilbert, 2003). Such affective forecasting may dampen the effects of pessimism, yet may contribute little to the resolution of the structural problems of the transport system.

Prospect theory provides other interesting insights. Some authors consider Prospect theory as an erroneous form of affective forecasting (see e.g. Kermer et al, 2006). Prospect theory depicts a probabilistic mind which is influenced by framing and values, which inform perceptions about relative gains or losses and thus contributes to risk-seeking or risk-averse behaviour (Kahneman and Tversky, 1979). Risk-seeking behaviour may be prompted by the desire to avoid losses, or due to endowment effects (Kahneman and Tversky, 1984). Sunken costs - either from an organisational perspective, e.g. infrastructure; or from an individual perspective; e.g. investments in cars - may thus inform both risk averse and loss averse riskseeking behaviour in municipal planning (see e.g. Gilbert and Wilson, 2000). For example, personal use of cars, together with the observed effects of seeing cars in locations around a 
town, may trigger the availability heuristic, perhaps generating a sense of inevitability about the presence and use of cars in urban settings, or pessimism about the likelihood of reducing or limiting their use. Personal investment in a car may incentivise use whilst simultaneously increasing the endowed utility of a car (even as its monetary value declines), thus influencing behaviour and creating a perception that the car is too valuable to lose.

This may lead to risk-seeking behaviour, in the sense that - rather than pursue policy objectives that focus squarely on reducing use of cars (as a vector for achieving a diverse range of targets and generating various co-benefits) - municipalities may prefer to emphasise other policies, such as those focusing on campaigns for behavioural change or future innovations. This may occur even though stakeholders understand that such approaches offer limited transformative potential or will make limited contributions to the achievement of local objectives and also global sustainability objectives.

This argument outlines one possible way to use political psychology to interpret municipal inaction or inertia when it comes to sustainable transport. However, there are many other avenues to explore; myopia, attribution errors or attribution substitutions are examples of other theoretical contributions that may complement or reinforce the effects of this argument (see e.g. Tetlock, 2003). Attribution errors may provide a partial explanation for the incongruence between respondents' views and behaviour.

Zaller and Feldman (1992) propose a different approach for understanding survey results, suggesting that opinions are formed and updated when respondents are asked questions and partly depend on framing effects. Thus, responses may provide limited insight or merely reflect incongruencies as they are framed in questions. Similarly, issues may appear more or less salient, depending on the framing or context. For the respondents of this survey, this may mean that the ways the questions were framed or their personal or professional context led them to respond in certain ways. As a well-informed group, one may expect the respondents to be aware of incongruencies in the relationship between policies and implementation, or inconsistencies between the targets set and the scale of the challenges faced.

Such awareness may inform the responses that produce incongruencies, rather than reflect ignorance concerning incongruencies (i.e. the respondents reproduce the inconsistencies they perceive); yet the opposite may also be the case (i.e. respondents may be unaware). Moreover, framing effects need not be bounded, in the sense of being limited to the questions on the paper; framing effects are also evident in society, in terms of the physical environment around us. For example, Pol (2002) writes that "The city as a physical structure serves to condition social interactions by either facilitating or impeding them. The physical shape of the city also molds attitudes toward the environment". In this way, the existing physical environment of the municipality and current behaviour of inhabitants may also frame the results. Such an effect may interact with the availability heuristic, leading to erroneous (or correct) assumptions about the potential for change. 
This highlights an important issue for the study of sustainable urban development, namely the ways in which physical framing effects influence psychology and assumptions about sustainability. Municipalities (and other governmental agencies) play a formal role in society and shape the composition of physical space through infrastructure investments, etc. As such, municipalities could play an influential role in steering and shaping citizen behaviour, either by permitting or placing limitations on different kinds of behaviour. This may be seen in, for example, restrictions on smoking in public places.

Thus, the formal role of the municipality should not be neglected, yet it may also be the case that municipalities choose not to make use of their influencing power. For example, with regard to existing infrastructure that is no longer considered desirable, yet which municipalities may regard as sunken costs, it should not be forgotten that non-decisions, indecision or inaction may be interpreted as permission to carry on. In other words, roads are invitations to drive; the same is true of sidewalks or cycle paths. Should a municipality sincerely wish to contribute to sustainable development or sustainable transport, it has the option of using relatively simple means - i.e. to limit access for cars on roads and improve infrastructure for pedestrians and other modes of transport.

Respondents to this survey seemed not to believe that such an approach was likely to be implemented or succeed, in spite of their apparent interest in the idea. Thus, it is tempting to conclude that other kinds of assumptions play an influential role in shaping non-decisions or inaction about sustainable transport. Assumptions about public opinion and perceptions about the possible public reaction to significant changes or interventions surely play an influential role, likewise assumptions about economic or social impacts, or concerns about the uncertain effects of a transition. Nevertheless, it is unclear to what extent such assumptions are grounded in reality and reflect actual opinions, nor the extent of stakeholders' willingness to engage in such discussions. Policy-making appears constrained in certain ways, by assumptions about an elephant that may or may not be in the room. This means that, despite policy documents and respondents indicating a preference for prioritisation of walking, cycling and public transport at the expense of cars, there is limited political will to achieve a transition to more sustainable transportation.

\section{Conclusions}

This study aimed to explore the behaviour and opinions of a group of "key informants", in order to identify incongruencies and illustrate ways in which political psychology may provide insights that enrich our understanding of municipal policies and practice. It should be noted that, by focusing on political psychology, this study may appear to have downplayed the importance of political dynamics, institutions, and other factors that may influence policies, behaviour and opinions at the municipal level. This was not the intention 
of the authors, who - as noted in the Introduction - recognise the importance of such factors. Indeed, the paper aims to complement such perspectives with new insights.

Nevertheless, the sample size for this experimental study was small, and the results provide only an indicative insight into the ways stakeholders reason around complex issues such as sustainable urban development and transport planning. Moreover, the limited scope of the survey means that wider issues pertaining to issues such as authority and mandate were not addressed. For example, the ways that regulatory powers differ for different modes of transport were not considered (i.e. other public authorities or regulatory bodies may influence planning and limit the scope of municipal action). In a larger study, such issues could be explored in more detail. Similarly, more detailed assessment of possible variations between categories of respondent could be made, to investigate if other factors, such as age or gender, are influential. Despite such limitations, the study illustrates some ways in which theoretical perspectives from political psychology may contribute to understanding of the political and behavioural influences shaping strategic planning processes for sustainable urban development and sustainable transportation. In particular, political psychology provides insights into the ways in which underlying assumptions linked to norms, emotions, values, and heuristics influence behaviour and decisions. Such insights may provide partial explanations as to why inertia or indecision is observed in the face of complex decisions, decisions for which - despite there being relative consensus over the need for action and the implications of inaction - the political implications of effective action are perceived or assumed to be unpalatable. As a consequence, trade-offs occur, in which viable policy options are discounted, meaning that outcomes often counteract the stated intentions and objectives that motivate action in the first place, as well as the preferences of participants. It is risky to draw large conclusions from such a small sample, yet the study illustrates the potential value of developing larger studies on this and similar topics. Sustainable urban development and particularly sustainable transport are issues of considerable importance, which require urgent, effective and comprehensive action; deferred action or partial, limited measures only increase the overall scale of the challenge facing human societies. Thus, it is vital to increase understanding of the ways in which individuals - inside and outside of processes - understand sustainability, value different alternative visions of urban space, interpret political decisions and make decisions accordingly. Understanding the ways in which incongruencies influence processes may provide a mechanism for improving both the processes and their outcomes, in order to ensure that strategic planning processes deliver not just the a new variant of the status quo, but the future participants desire.

\section{Acknowledgements}

The authors wish to thank five anonymous reviewers for constructive input, as well as Patrick Fournier of the Université de Montréal for his comments on an early draft, and participants at the Tyndall Ph.D. Conference, University of Manchester, 23-25 April 2014, for their comments and suggestions. 


\section{References}

Altemeyer, B. (1996). The Authoritarian Specter. Cambridge: Harvard University Press.

Althaus, S.L. (1998) Information Effects in Collective Preferences, American Political Science Review, 92, pp. 545-558.

Bahia Schlee, M., Tamminga, K.R., Tangari, V.R. (2012) A method for gauging landscape change as a prelude to urban watershed regeneration: The case of the Carioca river, Rio de Janeiro, Sustainability, 4(9), pp. 2054-2098.

Baycan, T., Nijkamp, P. (2012) Critical success factors in planning and management of urban green spaces in Europe, International Journal of Sustainable Society, 4(3), pp. 209-225.

Ceron Castano, I., Wadley, D. (2012) Conceptualization and System Design in the Monitoring of Urban Form, Planning Practice \& Research, 27(5), pp. 495-511.

Cook, I.R., Swyngedouw, E. (2012) Cities, Social Cohesion and the Environment: Towards a Future Research Agenda, Urban Studies, 49(9), pp. 1959-1979.

Ellis, R. (2011) Who's Participation? Who's Sustainability? A Critical Analysis of Initiatives for Urban Sustainability in India, Scottish Geographical Journal, 127(3), pp. 193-208.

Finn, D., McCormick, L. (2011) Urban climate change plans: How holistic?, Local Environment, 16(4), pp. 397-416.

Fredriksson, C. (2011) Planning in the 'New Reality'- Strategic Elements and Approaches in Swedish Municipalities, Doctoral dissertation, Stockholm: KTH.

Gilbert, D. T., Wilson, T. D. (2000) Miswanting: Some problems in the forecasting of future affective states. In J. Forgas (Ed.), Thinking and feeling: The role of affect in social cognition. Cambridge:

Cambridge University Press.

Hermann, Margaret G. (1986) What is Political Psychology?, in M. Hermann (ed.), Political Psychology, San Francisco: Jossey-Bass.

House, R.J., Howell, J.M. (1992) Personality and charismatic leadership, Leadership Quarterly, 3(2), pp. 81-108.

International Energy Agency (IEA), (2013) Energy Policies of IEA Countries: Sweden, 2013 Review, Paris: International Energy Agency.

Johnson, F.X., Silveira, S. (2014) Pioneer countries in the transition to alternative transport fuels: Comparison of ethanol programmes and policies in Brazil, Malawi and Sweden, Environmental Innovation and Societal Transitions, 11, pp. 1-24.

Kahneman, D. (2011) Thinking, fast and slow, New York: Farrar, Straus and Giroux.

Kahneman, D., Tversky, A. (1973) Availability: A heuristic for judging frequency and probability, Cognitive Psychology, 5(1), pp. 207-233. 
Kahneman, D., Tversky, A. (1979) Prospect Theory: An Analysis of Decision Under Risk, Econometrica, XLVII, pp. 263-291.

Kahneman, D., Tversky, A. (1984) Choices, Values and Frames, American Psychologist, 39(4), pp. 341350.

Kermer, D.A., Driver-Linn, E., Wilson, T.D. Gilbert, D.T. (2006) Loss Aversion Is an Affective Forecasting Error, Psychological Science, 17(8), pp. 649-653.

Markman, K.D., Tetlock, P.E. (2000) 'I couldn't have known' : Accountability, foreseeability and counterfactual denials of responsibility, British Journal of Social Psychology, 39, pp. 313-325.

McManus, P. (2012) Measuring Urban Sustainability: the potential and pitfalls of city rankings, Australian Geographer, 43(4), pp. 411-424.

McQuire, W.J. (1993) The Poly-Psy Relationship, in S. Iyengar \& W.J. McGuire (eds), Explorations in Political Psychology, Durham: Duke University Press.

Milgram, S. (1974) Obedience to Authority: An Experimental View, New York: Harper.

Mori, K., Christodoulou, A. (2012) Review of sustainability indices and indicators: Towards a new City Sustainability Index (CSI), Environmental Impact Assessment Review, 32(1), pp. 94-106.

Norrköpings kommun, (2011) Municipal Target 15 / Övergripande mål 15 i Övergripande mål 20112014, http://www.norrkoping.se/organisation/pdf/mal-regler/malomraden/overgripande-mal_20112014.pdf (accessed 9 January 2015).

Norrköpings kommun, (2011) Guidelines for Transport / Riktlinjer för trafik i Norrköpings kommun, Norrköping: Stadsbyggnadskontoret.

Pol, E. (2002) The Theoretical Background of the City-Identity-Sustainability Network, Environment and Behavior, 34(8), pp. 8-25.

Rydin, Y. (2010) Governing for Sustainable Urban Development. London: Earthscan.

Smith, R., Wiek, A. (2012) Achievements and opportunities in initiating governance for urban sustainability, Environment and Planning C: Government and Policy, 30(3), pp. 429-447.

Swedish Transport Administration / Trafikverket, (2014) Transportsektorns utsläpp, http://www.trafikverket.se/Privat/Miljo-och-halsa/Klimat/Transportsektorns-utslapp/ (accessed 4 September 2014).

Sunstein, C.R. (2003) Moral Heuristics, John M. Olin Law \& Economics Working Paper No. 180 (2D Series).

Tetlock, P.E. (2003) Thinking the unthinkable: sacred values and taboo cognitions, TRENDS in Cognitive Sciences, 7(7), pp. 320-324.

Turcu, C. (2012) Local experiences of urban sustainability: Researching Housing Market Renewal interventions in three English neighbourhoods, Progress in Planning, 78(3), pp. 101-150. 
United Nations, (1992) Earth Summit. Agenda 21. The United Nations programme for action from Rio.

United Nations Human Settlements Programme (UN-Habitat), (2011) Cities and Climate Change: Global report on human settlements 2011, London: Earthscan.

Vallance, S., Perkins, H.C., Bowring, J., Dixon, J.E. (2012) Almost invisible: Glimpsing the city and its residents in the urban sustainability discourse, Urban Studies, 49(8), pp. 1695-1710.

Wilson, T.D., Gilbert, D.T. (2003) Affective Forecasting. Advances in Experimental Social Psychology, 35, pp. 345-411.

Wollmann, H. (2008) Comparing Local Government Reforms in England, Sweden, France and Germany: www.wuestenrot-stiftung.de/download/local-government (accessed 15 January 2014).

Zaller, J., Feldman, S. (1992) A Simple Theory of the Survey Response: Answering Questions versus Revealing Preferences, American Journal of Political Science, 36 (3), pp. 579-616. 